\title{
A Numerical Simulation of Extratropical Storm Surge and Hydrodynamic Response in the Bohai Sea
}

\author{
Yumei Ding ${ }^{1,2}$ and Lei Ding ${ }^{3}$ \\ ${ }^{1}$ Physical Oceanography Laboratory, Ocean University of China, Qingdao 266100, China \\ ${ }^{2}$ School of Science, Tianjin University of Science and Technology, TEDA, Tianjin 300457, China \\ ${ }^{3}$ College of Marine Science and Engineering, Tianjin University of Science and Technology, TEDA, Tianjin 300457, China
}

Correspondence should be addressed to Yumei Ding; dingym@tust.edu.cn

Received 24 September 2013; Revised 15 January 2014; Accepted 19 January 2014; Published 10 March 2014

Academic Editor: Qi-Ru Wang

Copyright (C) 2014 Y. Ding and L. Ding. This is an open access article distributed under the Creative Commons Attribution License, which permits unrestricted use, distribution, and reproduction in any medium, provided the original work is properly cited.

\begin{abstract}
A hindcast of typical extratropical storm surge occurring in the Bohai Sea in October 2003 is performed using a three-dimensional (3D) Finite Volume Coastal Ocean Model (FVCOM). The storm surge model is forced by $10 \mathrm{~m}$ winds obtained from the Weather Research Forecasting (WRF) model simulation. It is shown that the simulated storm surge and tides agree well with the observations. The nonlinear interaction between the surge and astronomical tides, the spatial distribution of the maximum surge level, and the hydrodynamic response to the storm surge are studied. The storm surge is the interaction of the surge and the astronomical tides. The currents change rapidly during the storm surge and turn to be the unidirectional at some places where the tidal currents are usually rectilinear. The results show that the local surge current velocity in each depth, with a magnitude of the same order as the astronomic tidal currents, increases or decreases rapidly depending on the relationship between the winds and current directions. Furthermore, the current pattern gets more complicated under the influence of the direction of the winds, which might affect sand movement in the coastal water of the Bohai Sea.
\end{abstract}

\section{Introduction}

Storm surge is defined as the abnormal change in sea level that may accompany either extratropical or tropical storm [1]. Storm surges have a hazardous impact in coastal regions, threatening infrastructures, ecosystems, and even human lives. The investigation of the processes related to the generation of storm surge and their temporal variability has become a major issue in climate research. The risks of flooding of storm surge increase in many regions, enhancing the effects and possible damages caused by extreme high waters. Extreme sea level events are commonly driven by the combination of tidal elevation and storm surge. While tidal oscillations are deterministic, the storm surge component depends on the forcing of atmospheric pressure and wind. In areas of large tidal amplitudes and shallow waters the tidesurge interaction may become significant. In such areas the storm surges represent a problem when they occur at the time of high waters [2].
China is one of the countries which are harmed by storm surge both tropical and temperate cyclones; the disaster of storm surge can occur every seasons and from south to north in China's coastal area. The frequency and the intensity of storm surge both increased in recent years. According to the series data of Ocean Disasters Reports in China, there are 44 sea disasters in China in 2011, and nearly 22 disasters induced by the storm surge. There are 62.07 million $\mathrm{RMB}$ for the sea damages and there are 48.81 million RMB because of the storm surge which occupies 78.6 percent in the sea disasters. The frequency, intensity, and direct economic losses of storm surge disasters have the increasing trend. Accordingly it is very important for economical, social, and ecological sustainable development along coastal areas of China to study storm surge disasters deeply.

The regions which are most frequently and seriously affected by the extratropical storm surge in China are the Laizhou Bay, Bohai Bay, and Haizhou Bay. Based on the statistics from 1950 to 1998 , there are 3,383 days typical 
extratropical storm surge that occurred in the Tianjin Tanggu Port in 49 years where the water level fluctuations exceeded 50 centimeters, and nearly 78 days water increase process occurred annual of Tianjin coastal. During these days, nearly 495 days water increase process exceeded 100 centimeters, and nearly about 9.3 days annual [3].

The Bohai Sea (see Figure 1), is located in $37^{\circ} 07^{\prime} \mathrm{N}$ $41^{\circ} \mathrm{N}$ and $117^{\circ} 35^{\prime} \mathrm{E}-121^{\circ} 10^{\prime} \mathrm{E}$, whose total area is $77,000 \mathrm{~km}^{2}$ and average depth is $18 \mathrm{~m}$. The Bohai Sea is one of China's marginal seas and usually harmed by storm surge. Unlike the other marginal seas, the Bohai Sea is less susceptible to storm surges associated with tropical cyclones, because its latitudes are so high that only a few tropical cyclones are able to move northward far enough to generate storm surges along the coastal regions. The Bohai Sea frequently faces threats from extratropical storm surge and suffers a massive damage from its resulting storm surge. In the Bohai Sea, storm surges caused by extratropical cyclones are more common compared with those induced by tropical cyclones [4].

The study of storm surge has routinely been undertaken from the combination of tide and surge $[5,6]$ or from the output of the storm surge simulations [7] in order to reduce the loss of the storm surge. Storm surges have been studied intensively by a numerical method. But few of these studies take into consideration the distribution characteristics of the water level fluctuations and the hydrodynamic response on the storm surge model. This study will focus on the spatial distribution characteristics of the water level fluctuations and the hydrodynamic response on the storm surge simulation of the local coastline geometry in the Bohai Sea induced by extratropical cyclone.

In this work, a hindcast of typical extratropical storm surge occurring in the Bohai Sea in October 2003 is performed using a 3D FVCOM nonlinear barotropic model forced by $10 \mathrm{~m}$ winds. The output of this model is used to identify the characteristics of the surge level fluctuations and the hydrodynamic response on the storm surge simulation in the Bohai Sea.

This paper is organized as follows. The numerical models and the verification, with their corresponding forcing and outputs, are described in Section 2. In Section 3 the analysis of the surge level and the hydrodynamic response are considered for the storm surges simulation and the outputs of the simulation are performed. The conclusions are outlined in Section 4.

\section{The Model Formulation}

2.1. The Primitive Equations. FVCOM is an unstructuredgrid, finite-volume, free-surface, and three-dimensional primitive equations ocean model developed originally by Chen et al. [8]. The original version of FVCOM consists of momentum, continuity, temperature, salinity, and density equations and is closed physically and mathematically using the Mellor and Yamada level 2.5 turbulent closure scheme for vertical mixing and the Smagorinsky turbulent closure scheme for horizontal mixing. The merits of FVCOM are mainly associated with the triangular grids suiting well the

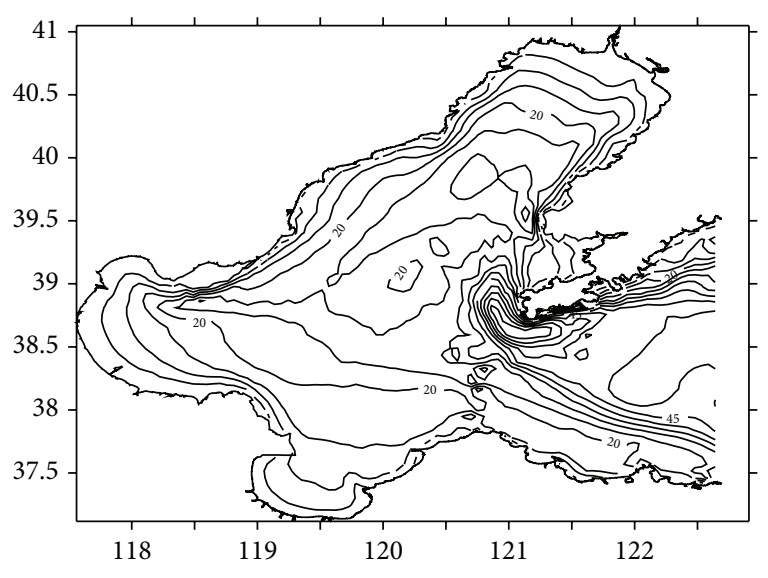

FIGURE 1: Geometry and bathymetry of the Bohai Sea.

complex geometry, and with the finite volume approach making possible good conservation behavior of the model. Mode splitting technique is applied to internal mode. 2D external mode is numerically integrated using a modified fourth-order Runge-Kutta time-stepping scheme, while 3D internal mode is integrated using second-order Runge-Kutta time-stepping scheme. The point wetting-drying treatment technique is included to predict the water covering and uncovering progress in the inter tide zone. The governing equations consist of the following momentum, continuity, temperature, salinity, and density equations:

$$
\begin{gathered}
\frac{\partial u}{\partial t}+u \frac{\partial u}{\partial x}+v \frac{\partial u}{\partial y}+w \frac{\partial u}{\partial z}-f v \\
=-\frac{1}{\rho_{0}} \frac{\partial P}{\partial x}+\frac{\partial}{\partial z}\left(K_{m} \frac{\partial u}{\partial z}\right)+F_{u} \\
\frac{\partial v}{\partial t}+u \frac{\partial v}{\partial x}+v \frac{\partial v}{\partial y}+w \frac{\partial v}{\partial z}+f u \\
=-\frac{1}{\rho_{0}} \frac{\partial P}{\partial y}+\frac{\partial}{\partial z}\left(K_{m} \frac{\partial v}{\partial z}\right)+F_{v} \\
\frac{\partial P}{\partial z}=-\rho g \\
\frac{\partial u}{\partial x}+\frac{\partial v}{\partial y}+\frac{\partial w}{\partial z}=0, \\
+u \frac{\partial \theta}{\partial x}+v \frac{\partial \theta}{\partial y}+w \frac{\partial \theta}{\partial z}=\frac{\partial}{\partial z}\left(K_{h} \frac{\partial \theta}{\partial z}\right)+F_{\theta} \\
\frac{\partial S}{\partial t}+u \frac{\partial S}{\partial x}+v \frac{\partial S}{\partial y}+w \frac{\partial S}{\partial z}=\frac{\partial S}{\partial z}\left(K_{h} \frac{\partial z}{\partial z}\right)+F_{S} \\
\rho=\rho(T, S) .
\end{gathered}
$$

where $x, y$, and $z$ are the east, north, and vertical axis in the Cartesian coordinate system. $u, v$, and $w$ are the $x, y$, and $z$ velocity components; $\theta$ is the temperature; $S$ is the salinity; $\rho$ is the density; $P$ is the pressure; $f$ is the Coriolis parameter; $g$ is the gravitational acceleration; $F_{u}, F_{v}, F_{\theta}$, and $F_{S}$ represent 


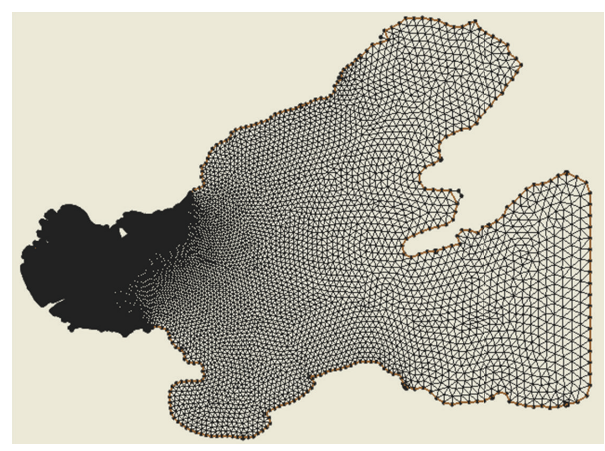

FIgURE 2: The grids used for the simulations.

the horizontal momentum, thermal, and salt diffusion terms. $K_{m}$ and $F_{h}$ are the thermal vertical eddy diffusion coefficient and the vertical eddy viscosity coefficient.

2.2. The Model Set. The geometry and bathymetry of the Bohai Sea are shown in Figure 1. The gridded bathymetric data of year 2000 were obtained by interpolating the Hydrological Atlas data [9]. The data of coastline of year 2000 is extracted from the information of the NASA Landsat TM/ETM sensor by using the Canny operator [10].

The model domains the whole Bohai Sea and the open boundary arching outside of the Bohai Strait. The grid resolution remains at $1 \mathrm{~km}$ near shoreline of the Bohai Bay and gradually increases to about $3-5 \mathrm{~km}$ in the central Bohai Sea and at last remains about $10 \mathrm{~km}$ in the open boundary to fit the complicated coastline (Figure 2). The horizontal triangular grid has 12824 nodes and 24656 elements. The initial field of water velocity is set to zero in this study. Five sigma levels are used in the vertical plane. The external time step is 3 seconds, and the ratio of internal time step to external time step is 10 .

In this work, the ocean model has been forced by 3-hourly $10 \mathrm{~m}$ winds calculated by the Weather Research Forecasting (WRF) model simulation, with a spatial resolution of $0.1^{\circ}$ and $0.1^{\circ}$ in latitude and longitude, respectively. The elevation clamped open boundary condition is given. The time-dependent water elevations consist of eight main astronomical tides, that is, $M_{2}, S_{2}, N_{2}, K_{2}, K_{1}, O_{1}, P_{1}$, and $Q_{1}$ calculated from OTPS (OSU Tidal Prediction Software, http://volkov.oce.orst.edu/tides/) along the open boundary. Hourly storm surge model outputs have been stored for the whole domain.

2.3. Model Verification. Prior to simulating the storm surges, we test the model simulations of tides. Figures 3 and 4 show the Co-amplitude and Co-phase of $M_{2}$ and $K_{1}$ constituents in the Bohai Sea are in well accordance with the references tidal wave propagations based on observations [11, 12]. Two amphidromic points were found in $M_{2}$ tide and single amphidromic point in $K_{1}$. The tidal level was about $4 \mathrm{~m}$ in the top of the Liaodong and Bohai Bay. The hourly water level outputs from the tide simulation have been stored for the whole domain.

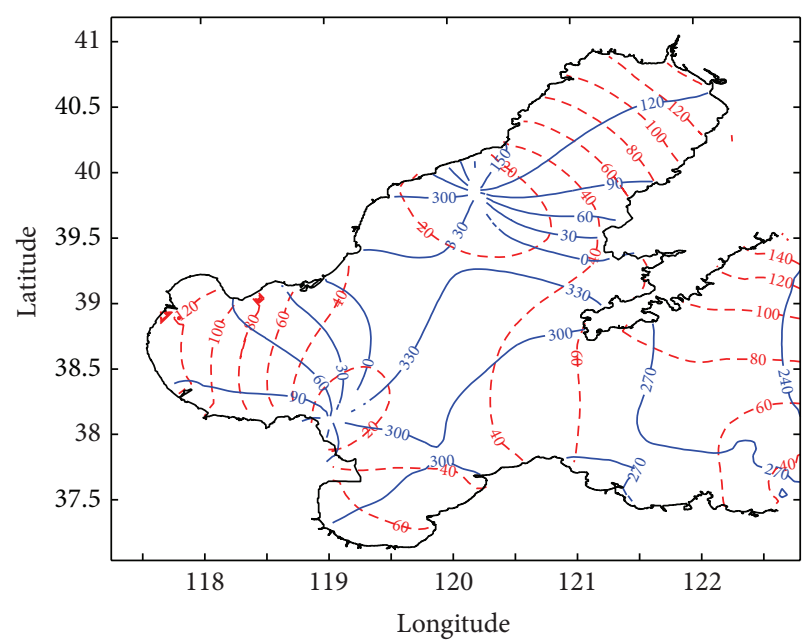

Figure 3: Co-amplitude and Co-phase of $M_{2}$ constituent in the Bohai Sea.

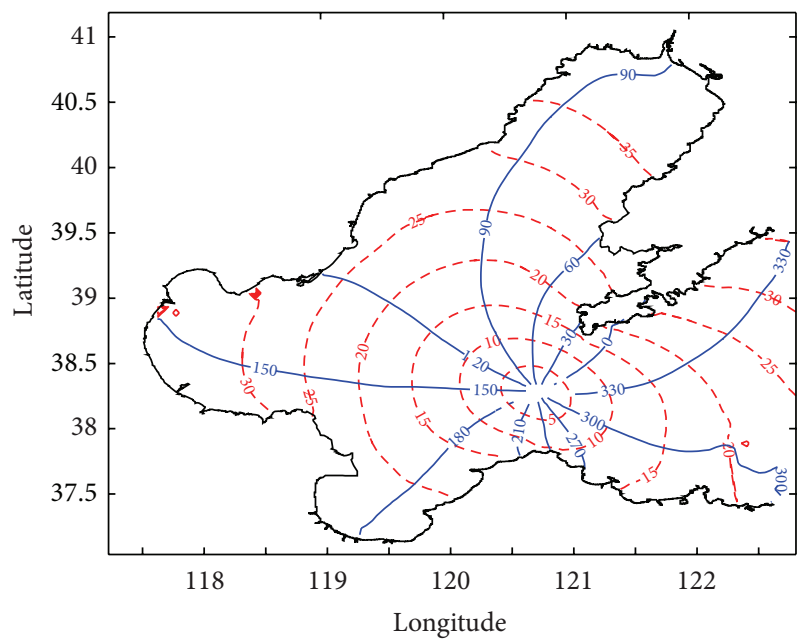

FIgURE 4: Co-amplitude and Co-phase of $K_{1}$ constituent in the Bohai Sea.

For the storm surge simulations, the model is driven by the wind stress from the WRF data, plus astronomical tides (elevations at the open boundaries). The model begins at 00 GMT on October 1, 2003, and ends at 23 GMT on October 31, 2003 (a total run duration of 31 days). To test the surge model's modeling ability, the model system is initially applied to reproduce the storm surge generated from October 10 to October 13 in 2003. The surge level is the water level outputs from the storm surge simulation minus the water level outputs from the tide simulation.

We select the Tanggu Port located in the north west of the Bohai Sea, as an example for comparison with the simulation. A detailed validation of the hindcast against observation is presented in Figure 5, which shows that the surge level simulation is in good agreement with the observation, both in storm surge amplitude and phase; it captures the initial rapid increase of surge level very closely. The model simulation peaks at 1 o'clock on October 11, 2003, with a storm surge level 


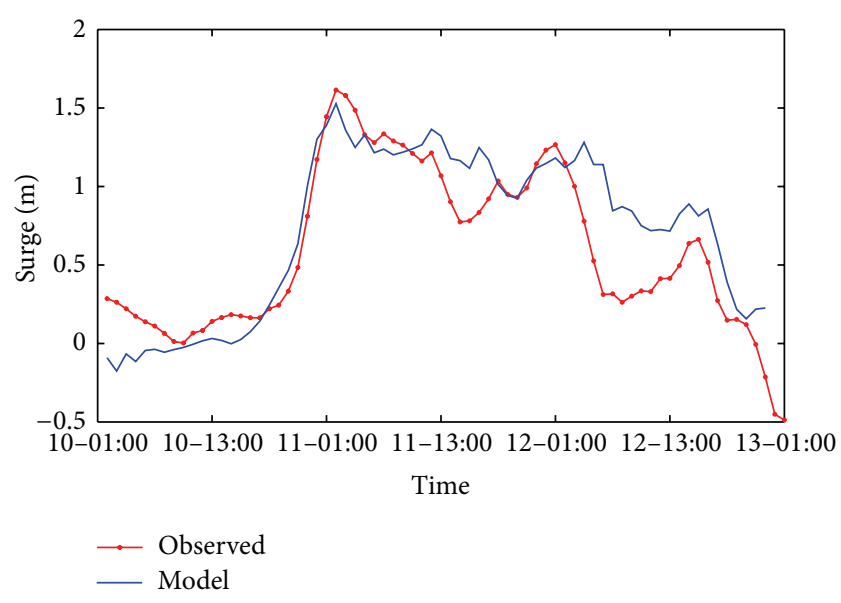

Figure 5: Time-series comparisons of observed (red) and model (blue) simulated surge levels at Tanggu Port.

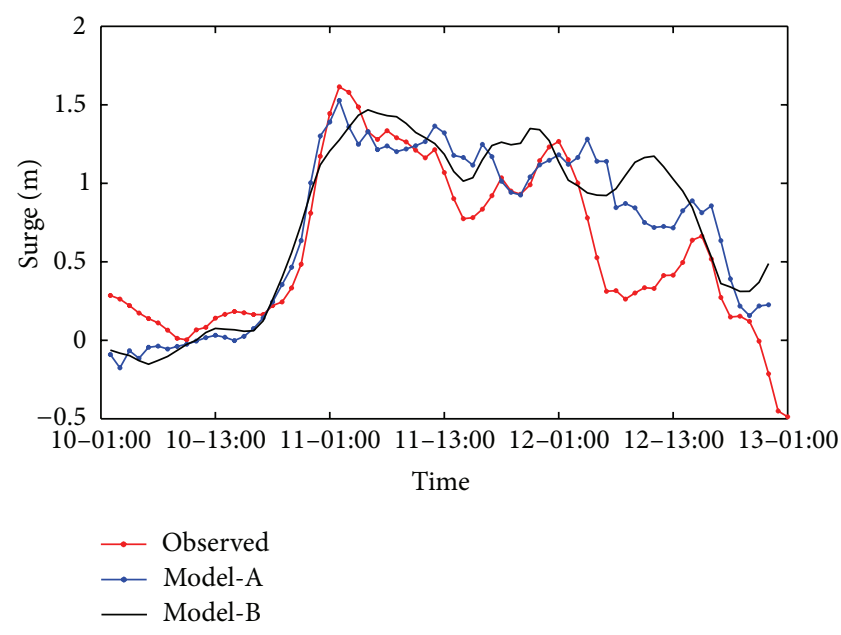

FIgURE 6: Time-series comparisons of observed (red), model-A (blue), and model-B (black) simulated surge levels at Tanggu Port.

of $1.52 \mathrm{~m}$, about $0.09 \mathrm{~m}$ lower than observed. Even though this validation does not focus on the extreme events, this is not a major problem here, as far as we are interested in the distribution of the spatial distribution characteristics of the water level fluctuations and the hydrodynamic response of the surge model but not in the absolute values.

\section{Result and Discussion}

3.1. The Nonlinear Interaction between Storm Surges and Astronomical Tides. For these storm surge simulations, three baseline runs are performed: (a) the model forced by astronomical tides and wind (called model-A); (b) the model forced only by wind but no astronomical tides (called modelB); (c) the model forced only by astronomical tides but no wind (called model-C). The surge levels of model-A are the sea elevation from the output of model-A minus the sea elevation from the model-C, and the surge levels of model$B$ are the sea elevation from the output of model-B.
We select the Tanggu Port as an example for comparison with the simulation. As shown in Figure 6, the surge level from model-A simulation is in good agreement with the observation. The surge level peaks at 1 o'clock on October 11,2003 . Then the simulation and the observation show the surge levels decreasing in 48 hours, followed by a lower decrease along with tidal oscillations. In comparison with the model-A simulation, the surge level from model-B simulation underestimates the peak with the storm surge level of $1.40 \mathrm{~m}$, about $0.21 \mathrm{~m}$ lower and 4 hours later than observed. It is concluded that the nonlinear effect plays important roles in the storm surge. The results show that the storm surge is the interaction of the astronomical tides and the storm surges.

3.2. The Characteristics of the Surge Level Fluctuations. Figure 7 shows the surge level fluctuations and the wind stress vector in the Bohai Sea at typical time during the storm surge. The influential range of the storm surge involves the whole Bohai Sea. The surge level fluctuation in the coastal areas of the Bohai Bay and Laizhou Bay shows a trend of ascending inside the bays and descending outside the bays. The cold air coming from the northeast plains flows through the Bohai Bay, and the wind direction is from east to northeast in the Bohai Bay. The storm surge's magnitude mainly depends on the wind stress, so the surge level is in proportion to the wind velocity, and the northeast direction is the main direction for the storm surge in the Bohai Sea. In the Liaodong Bay, surge current flows out of the bay because the long time northwest wind leaves from the coast areas; then the surge level reduces because of no additional water in the bay. Along with the northeast wind flowing down to the south, the surge current swarms into the Bohai Bay and Laizhou Bay quickly which leads to the surge level rise in the two bays. The direction of east wind flowing towards the shore is the main direction for the increasing of the surge level, whereas, because the west wind flows off the shore, the west direction is the main direction for the descending of the surge level.

The surge level begins increasing at the Tanggu Port under the effect of the east to northeast wind on October 10, 2003, later spreads to the north and the southwest of the Bohai Bay, and then peaks at 01 o'clock with a storm surge level of $1.52 \mathrm{~m}$. The surge level fluctuation goes on spreading to the north at the Jingtang Port and Qinhuangdao Port and then spreading to the south of the Bohai Sea, which peaks at 14 oclock with a storm surge level of $2.13 \mathrm{~m}$ at the Huanghua Port. The trend of the surge level is NE-SW direction. There are some upback oscillations in the storm surge. On October 12, 2003, with the east to northeast wind changing to northwest, the larger surge level grows from the southwest of the Bohai Sea to the Laizhou Bay, which peaks at 09 o'clock on October 12 at the Yangjiaogou Port. The trend of the surge level fluctuation changes to NW-SE direction, then the surge level slowly declines, and the water level fluctuation becomes revovery.

\subsection{The Distribution of the Maximum and the Minimum Surge} Level. Figure 8 is the distribution of the maximum surge level. The maximum surge level occurs in the Bohai Bay and Laizhou Bay with the maximum surge level of $0.8-2.1 \mathrm{~m}$, but 

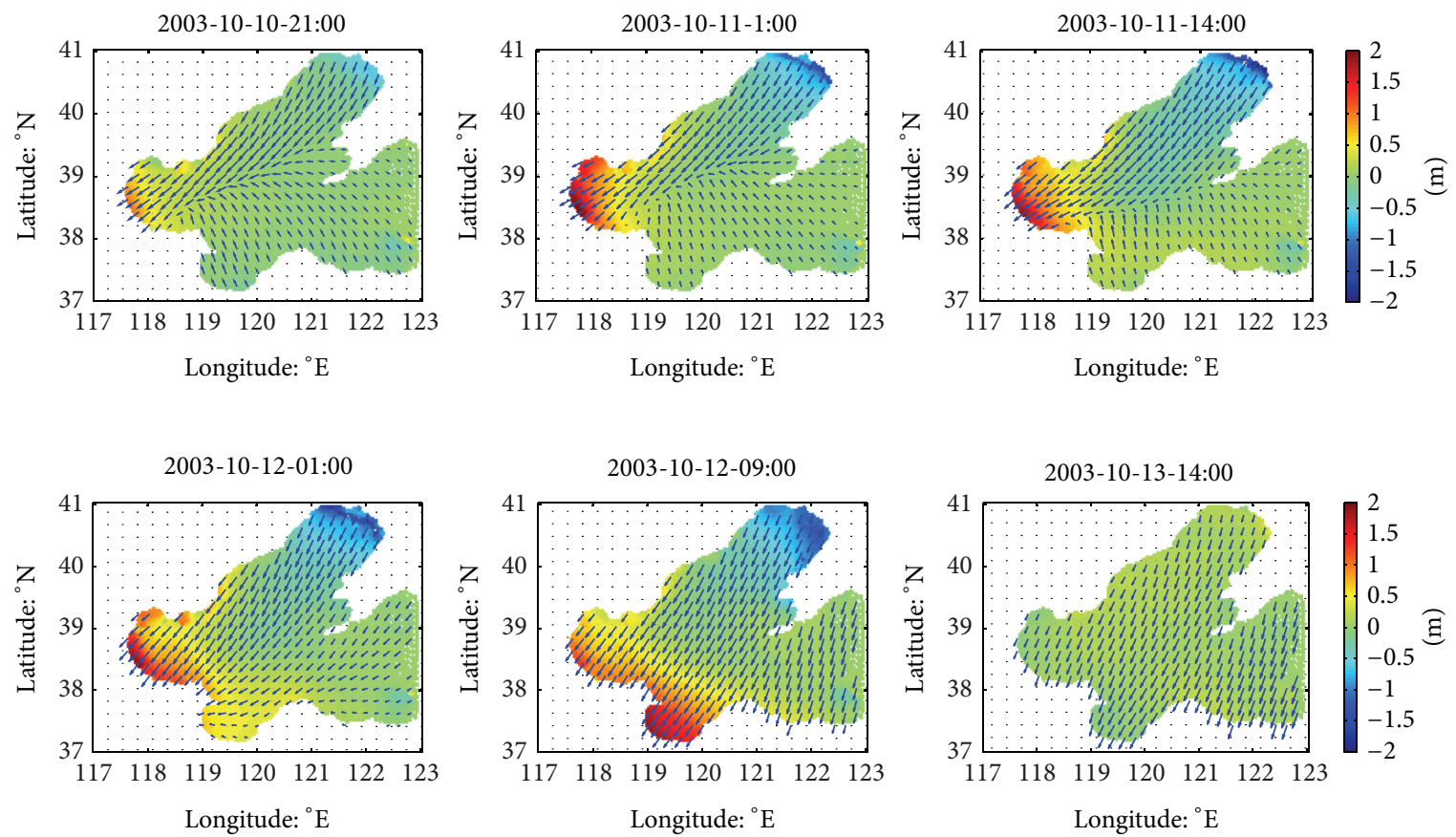

FIgURE 7: Surge level fluctuations and wind vector in the Bohai Sea at typical time during the storm surge.

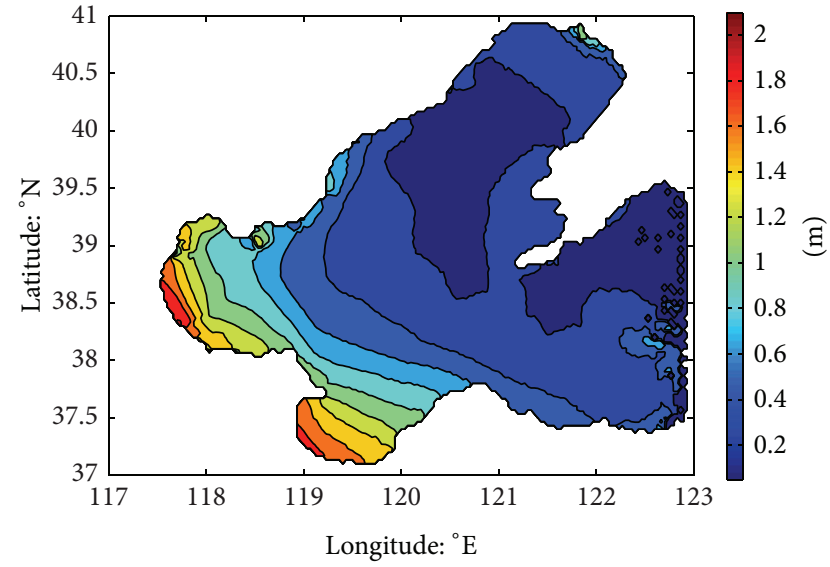

Figure 8: The distribution of the maximum surge level.

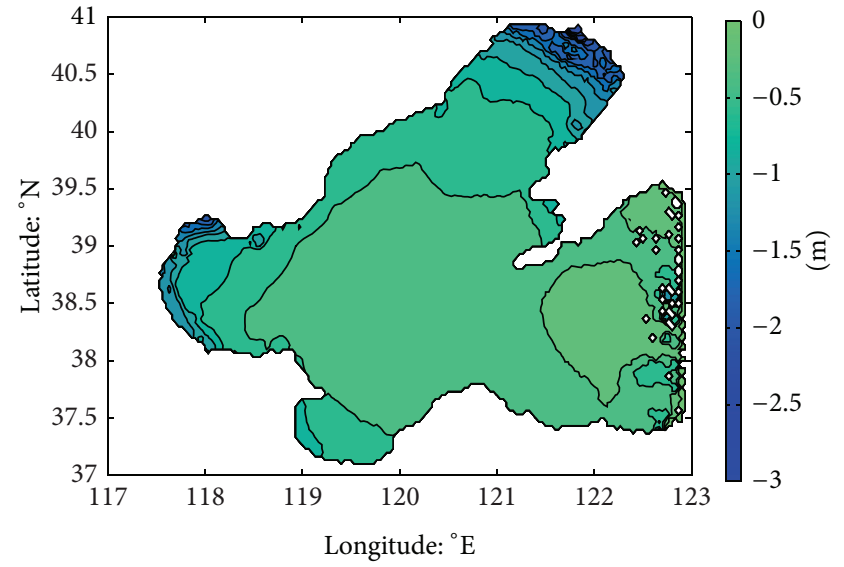

FIgURE 9: The distribution of the minimum surge level. the maximum surge level is $0.6-0.8 \mathrm{~m}$ in the Liaodong Bay. The trend of the maximum surge level is gradually increasing from the east to the west in the Bohai Bay and in NE-SW direction in the Laizhou Bay because of the effect of the geometry and the wind. The larger surge level occurs in the coastal areas of the Bohai Sea. The most severe areas affected by the storm surge are the Bohai Bay and Laizhou Bay.

Figure 9 indicates the distribution of the minimum surge level. The minimum surge level occurs at the Liaodong Bay and Bohai Bay with the minimum surge level of $-3.0 \mathrm{~m}$. The trend of the minimum surge level is gradually increasing from southwest to northeast at the Liaodong Bay. The most severe areas affected by the minimum surge level are the Liaodong Bay.
3.4. The Characteristics of the Surge Current. During the storm surge, the spatial-temporal characteristics of the surge current become more complicated (Figure 10). Comparative to the tidal current and the surge current, the direction of the tidal currents is the unidirectional flow at the Bohai Strait, but the direction of the surge currents is in an anticlockwise circulating current and the surge current values are bigger than the tidal currents. When the surge level is ascending, the currents in the north flow to the Liaodong Bay, while the currents in the west and the south flow to the Bohai Bay and Laizhou Bay. When the surge level is descending, the rotation current systems are shown in the Liaodong Bay, while the current along the coastal line flow to the southwest. In the Bohai Bay, the direction of the tidal current is parallel 

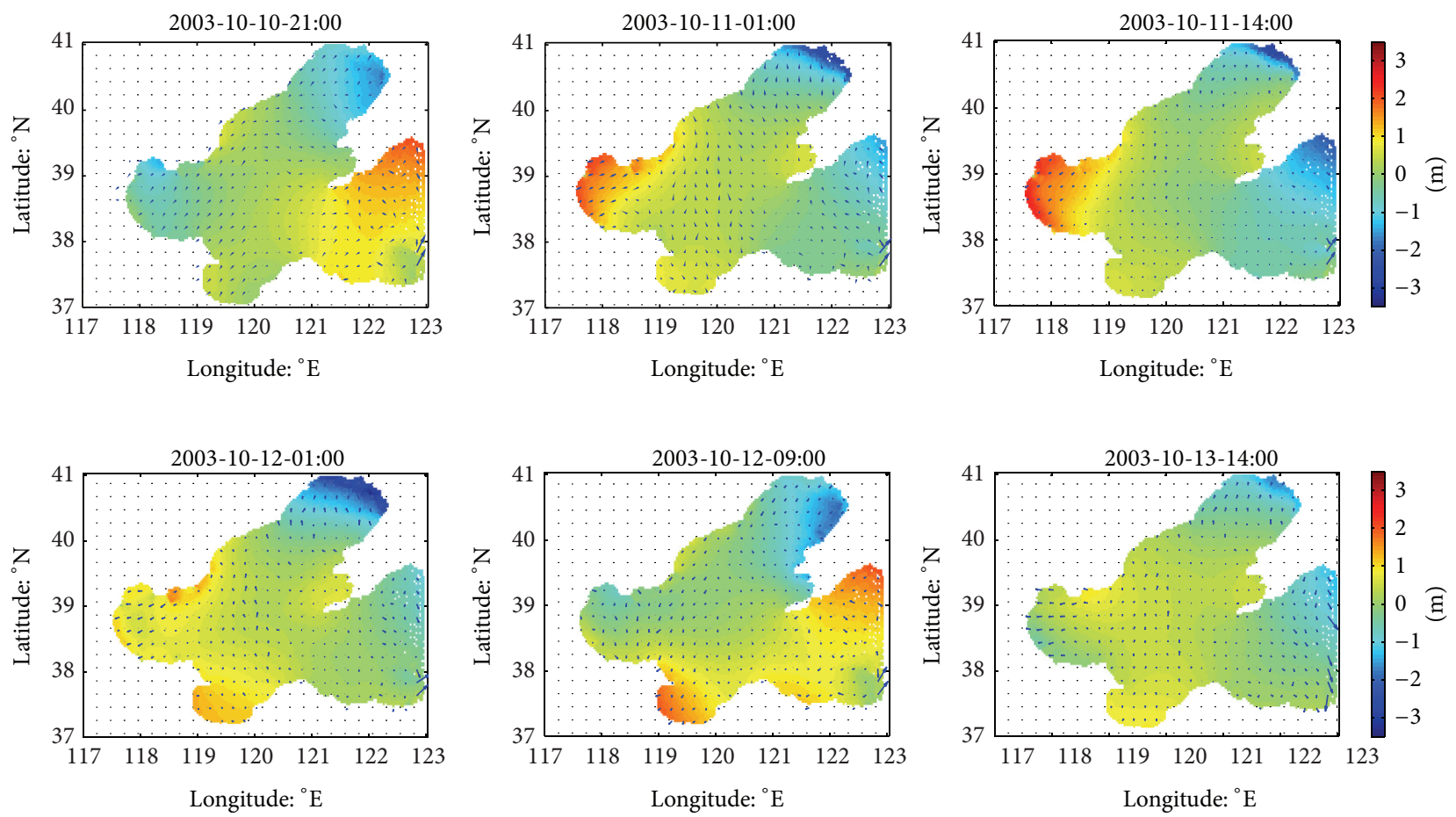

FIGURE 10: Water level fluctuations and the surge current in the Bohai Sea at typical time.

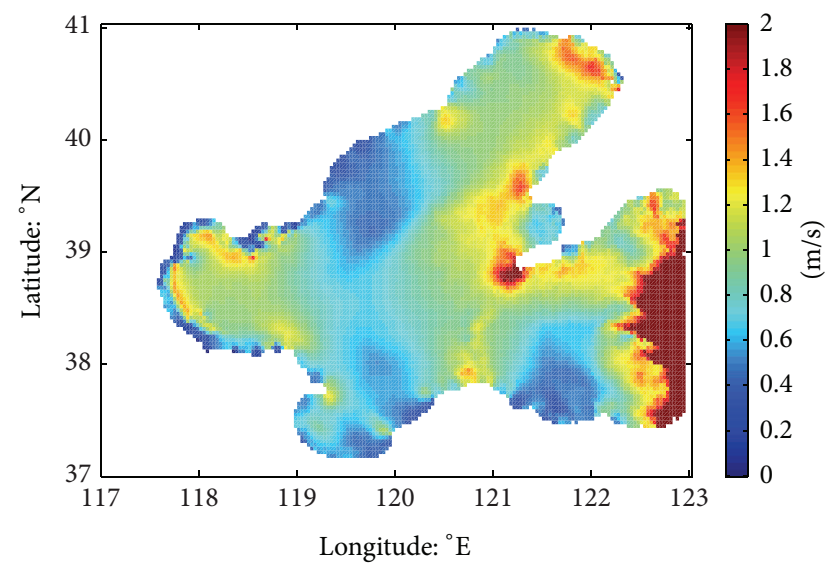

FIGURE 11: Distribution of the maximum tidal currents.

to the coastal line in the rectilinear current movement. The half-close circulating current systems are shown in the surge current field. In the north, the currents flow into the bay and in the south the currents flow out of the bay. In the Laizhou Bay, the tidal currents are in a rotation system, but the surge currents change to the half-close clockwise stable circulating currents from the mouth of the Yellow River through the top of the Laizhou Bay to the Bohai Strait.

The distribution of the maximum tidal currents in the Bohai Sea is shown in Figure 11. The strong tidal currents are located in the Bohai Bay and Liaodong Bay. The strongest current is at the Bohai Strait. These results are in good agreement with [12]. The weak current regions are located

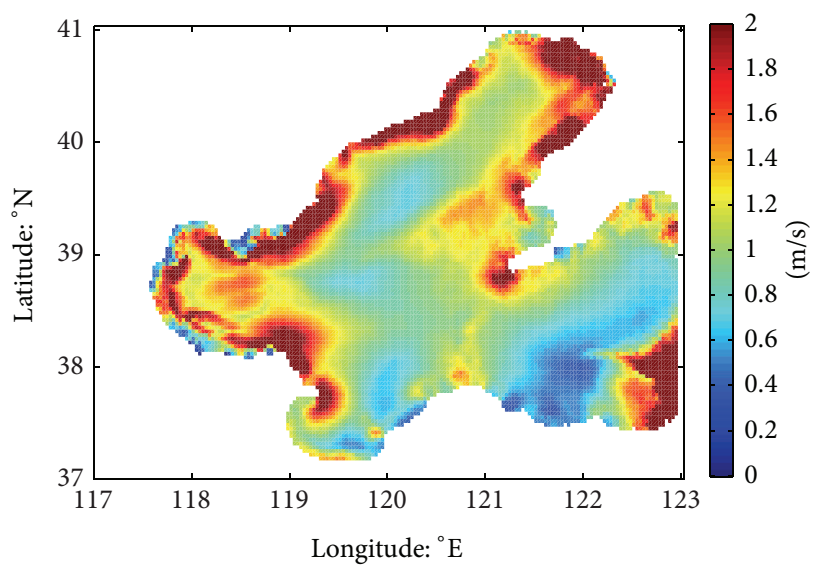

FIGURE 12: Distribution of the maximum surge currents.

in the middle of the Bohai Sea. The distributions of the maximum current of storm surge are shown in Figure 12. Comparative to the distribution of the tide, the strong current of the storm surge changes to the north and the northwest coastal areas of the Bohai Sea. The average maximum current of the storm surge is $0.5 \mathrm{~m} / \mathrm{s}$ larger than that of the tide. The weak surge current regions are the Bohai Strait and the middle of the Bohai Sea.

\subsection{The Characteristics of the Storm Surge Current in the Local} Coastal Areas. In the local coastal areas, the surge current becomes unidirectional at some places where the tidal current is usually rectilinear in each depth. We select the Huanghua 

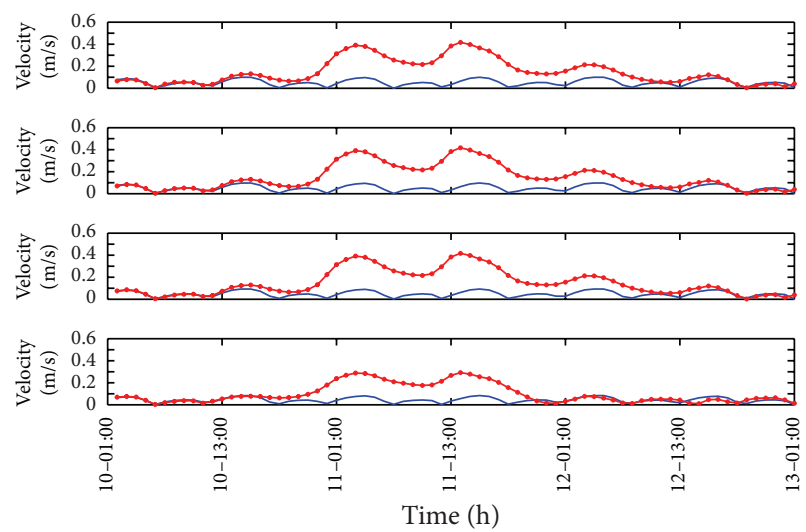

$$
\text { - Tide }
$$$$
\because \text { Surge }
$$
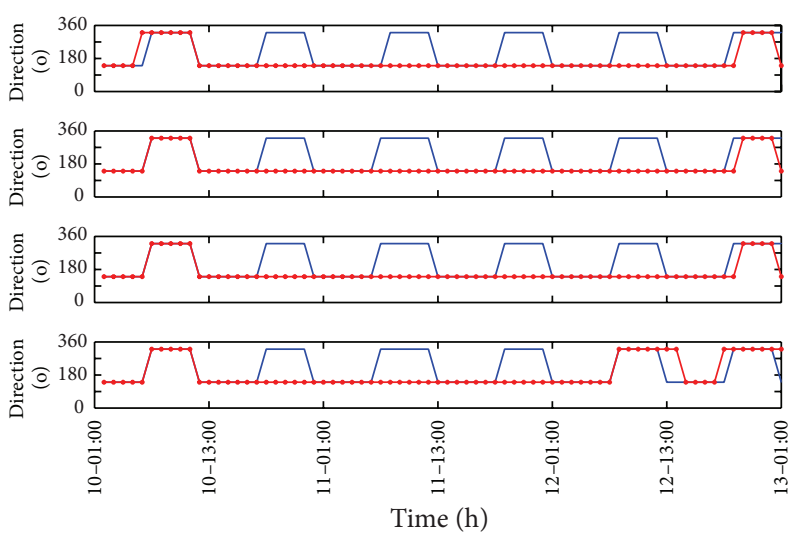

- Tide

$\longrightarrow$ Surge

FIGURE 13: Flow velocity and the direction effected by the storm surge in each depth at the Huanghua Port.
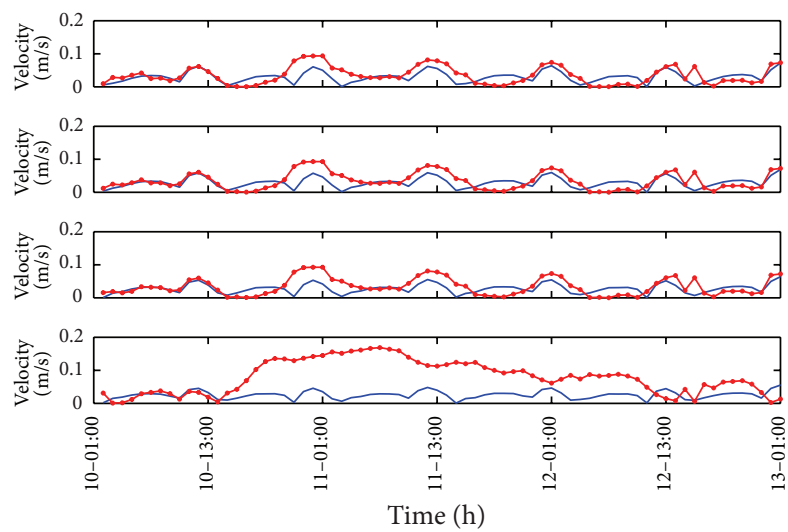

- Tide

$\rightarrow$ Surge
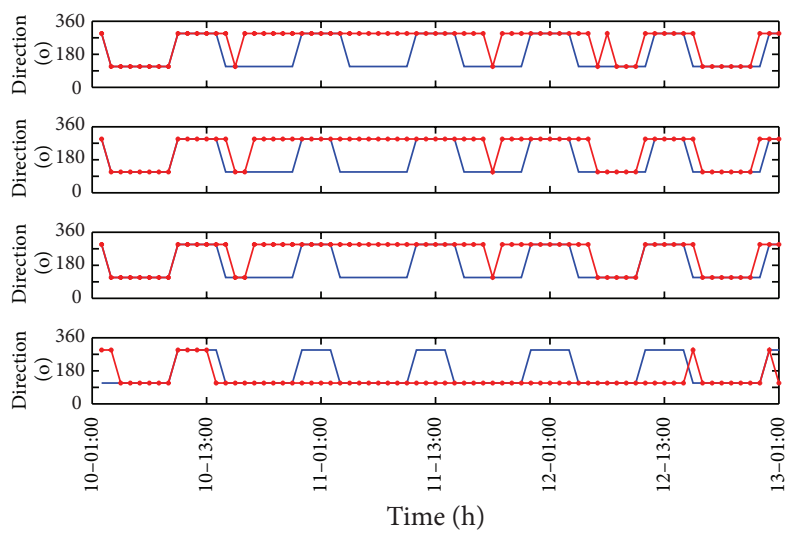

- Tide

$\rightarrow$ Surge

FIGURE 14: Flow velocity and the direction effected by the storm surge in each depth at the Tanggu Port.

Port and the Tanggu Port in the Bohai Sea to analyze the local hydrodynamic response to the storm surge. The results show that the local surge current velocity in each depth, with a magnitude of the same order as the astronomic tidal current, increases or decreases rapidly depending on the relationship between wind and current direction. The surge current pattern gets more complicated under the influence of direction-varying wind.

Figure 13 shows that the flow velocity and the direction are affected by the storm surge in each depth at the Huanghua Port. The surface flow to the bottom flow is from up to down the figure, respectively. In the initial stage of the storm surge, the flow of the storm surge is the same as the tidal current which is affected mainly by the astronomical tides. Later, the flow velocity and the direction change largely due to the severe storm surge. The surge flow velocity gradually increases from the bottom to the surface, and the surface surge flow velocity is larger than the bottom velocity owing to the effect of the wind. The surge flow velocity increases two times than the tidal current. The surge current turns to be unidirectional for about 48 hours, and the direction of the flow is NW-SE in each depth where the tidal current is usually rectilinear.

At the Tanggu Port, the flow velocity and the direction affected by the storm surge in each depth are shown in Figure 14. The surge flow velocity is larger than the tidal flow velocity, and the bottom surge flow velocity is much larger than that of the surface one. The surface flow is the same direction as the wind which called wind-driven current. The bottom flow is counter current. The surge current turns to be the unidirectional at the Tanggu Port where the tidal current is usually rectilinear for about 48 hours, and the direction of the wind-driven current is SE-NW direction in the surface and in the middle of the depth, but, in the bottom depth, the direction of the counter current is NW-SE direction. These complicated changes might affect sand movement in the coastal water of the Bohai Bay.

\section{Conclusions}

A three-dimension storm surge model is applied to investigate the distribution of the storm surge level and the hydrodynamic response in the Bohai Sea. The simulated surge levels 
and tidal elevations reproduced during the extratropical storm surge agree well with the field observations and the references. This study takes into consideration the nonlinear interaction between storm surge and astronomical tides, the distribution characteristics of the water level fluctuations, the spatial distribution of the maximum storm surge, and the hydrodynamic response to the storm surge. The storm surge is the interaction of the astronomical tides and surge. The water level fluctuation in the storm surge changes rapidly. The maximum surge level is in the Bohai Bay and Laizhou Bay, and the minimum surge level is in the Liaodong Bay and Bohai Bay. Further study focuses on the local hydrodynamic response to the storm surge. The surge current turns to be the unidirectional at some places where the tidal current is usually rectilinear. The results show that the local surge current velocity in each depth, with a magnitude of the same order as the astronomic tidal current, increases or decreases rapidly depending on the relationship between winds and current directions. Once the flow direction is the same as the wind direction, the surge flow velocity increases rapidly. Furthermore, the surge current pattern gets more complicated under the influence of the direction of the winds. These changes might affect sand movement in the coastal waters of the Bohai Sea.

\section{Conflict of Interests}

The authors declare that there is no conflict of interests regarding the publication of this paper.

\section{Acknowledgments}

This study was supported by the National Key Technology R\&D Program of China (2010BAC68B04) and the National Natural Science Foundation of China (40806008).

\section{References}

[1] L. Zheng, R. H. Weisberg, Y. Huang et al., "Implications from the comparisons between two- and three-dimensional model simulations of the Hurricane Ike storm surge," Journal of Geophysical Research: Oceans, vol. 118, no. 7, pp. 3350-3369, 2013.

[2] M. Marcos, G. Jordà, D. Gomis, and B. Pérez, "Changes in storm surges in southern Europe from a regional model under climate change scenarios," Global and Planetary Change, vol. 77, no. 3-4, pp. 116-128, 2011.

[3] S. H. Wu, X. N. Wang, S. Song, and M. Yuqian, "The general status and statistics of storm surges in the coast area of Tianjin," Marine Forecasts, vol. 19, pp. 29-35, 2002 (Chinese).

[4] P. Zhao and W. S. Jiang, "A numerical study of the effects of coastal geometry in the Bohai Sea on storm surges induced by cold-air outbreaks," Journal of Ocean University of China, vol. 10, no. 1, pp. 9-15, 2011.

[5] J. Proudman, "Oscillations of tide and surge in an estuary of finite length," Journal of Fluid Mechanics, vol. 2, pp. 371-382, 1957.

[6] D. Prandle and J. Wolf, "The interaction of surge and tide in the North Sea and River Thames," Geophysical Journal, vol. 55, no. 1, pp. 203-216, 1978.
[7] F. Y. Shi and W. X. Sun, "A variable boundary model of storm surge flooding in generalized curvilinear grids," International Journal for Numerical Methods in Fluids, vol. 21, no. 8, pp. 641651, 1995.

[8] C. S. Chen, H. D. Liu, and R. C. Beardsley, "An unstructured grid, finite-volume, three-dimensional, primitive equations ocean model: application to coastal ocean and estuaries," Journal of Atmospheric and Oceanic Technology, vol. 20, no. 1, pp. 159-186, 2003.

[9] B. H. Choi, Digital Atlas for Neighboring Seas of Korean Peninsula, Lab. for Coastal and Ocean Dynamics Studies, Sung Kyun Kwan University, 1999.

[10] X. M. Li, C. Z. Yuan, and Y. Y. Li, "Remote sensing monitoring and spatial-temporal variation of Bohai Bay coastal zone," Remote Sensing for Land \& Resources, vol. 25, pp. 156-163, 2013 (Chinese).

[11] H. J. Lee, K. T. Jung, J. K. So, and J. Y. Chung, "A threedimensional mixed finite-difference Galerkin function model for the oceanic circulation in the Yellow Sea and the East China Sea in the presence of M2 tide," Continental Shelf Research, vol. 22, no. 1, pp. 67-91, 2002.

[12] X. W. Bao, G. P. Gao, and J. Yan, "Three dimensional simulation of tide and tidal current characteristics in the East China Sea," Oceanologica Acta, vol. 24, no. 2, pp. 135-149, 2001. 


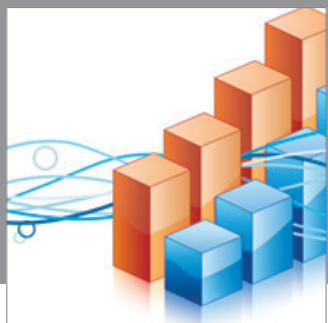

Advances in

Operations Research

mansans

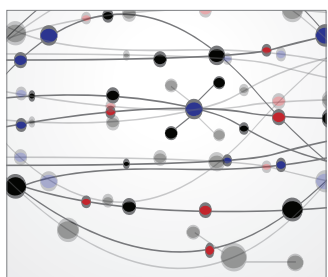

The Scientific World Journal
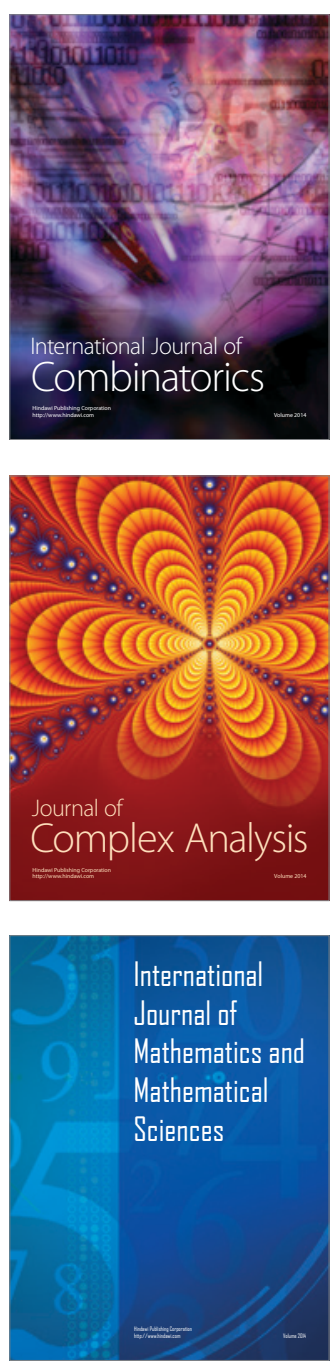
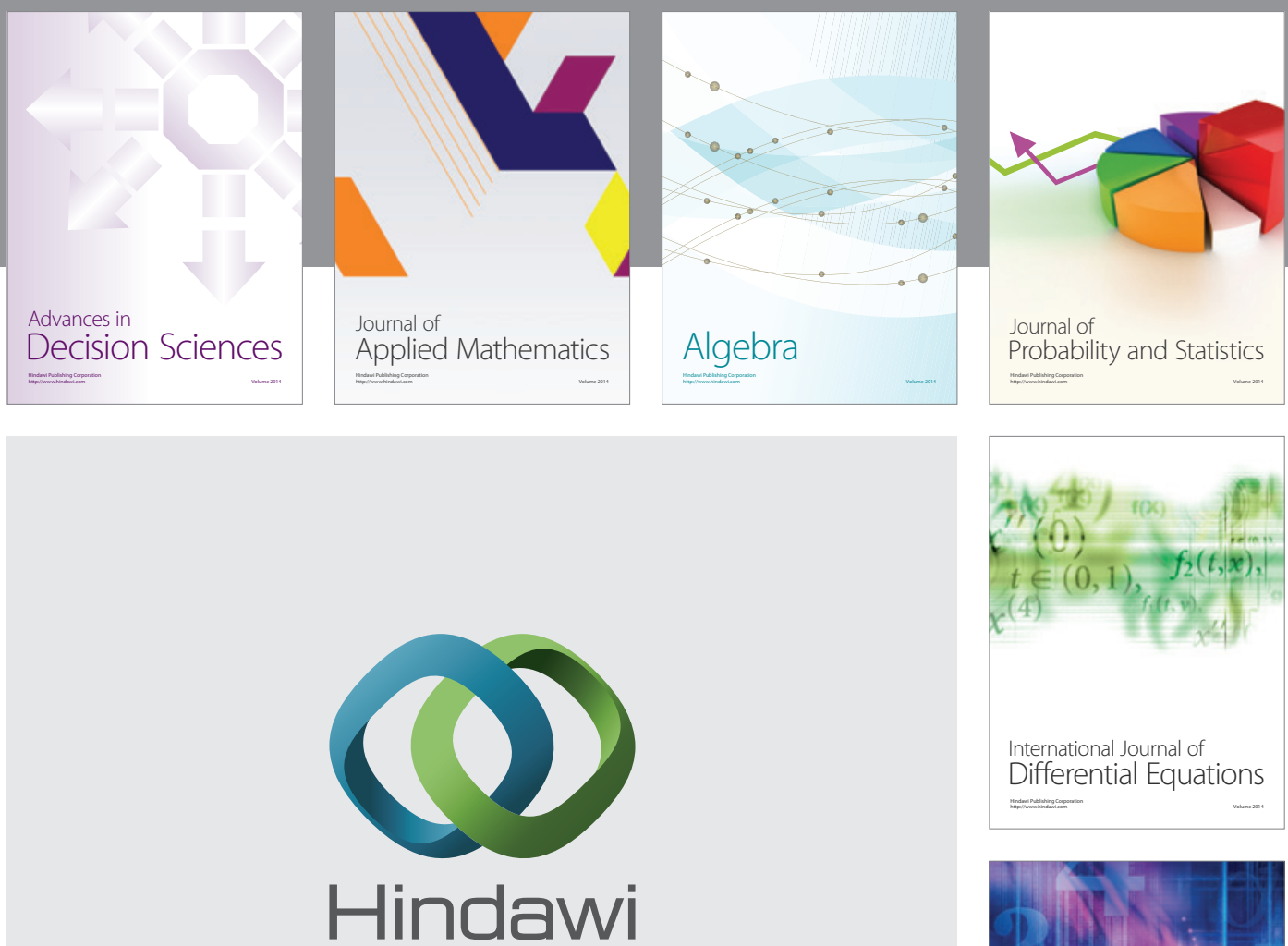

Submit your manuscripts at http://www.hindawi.com
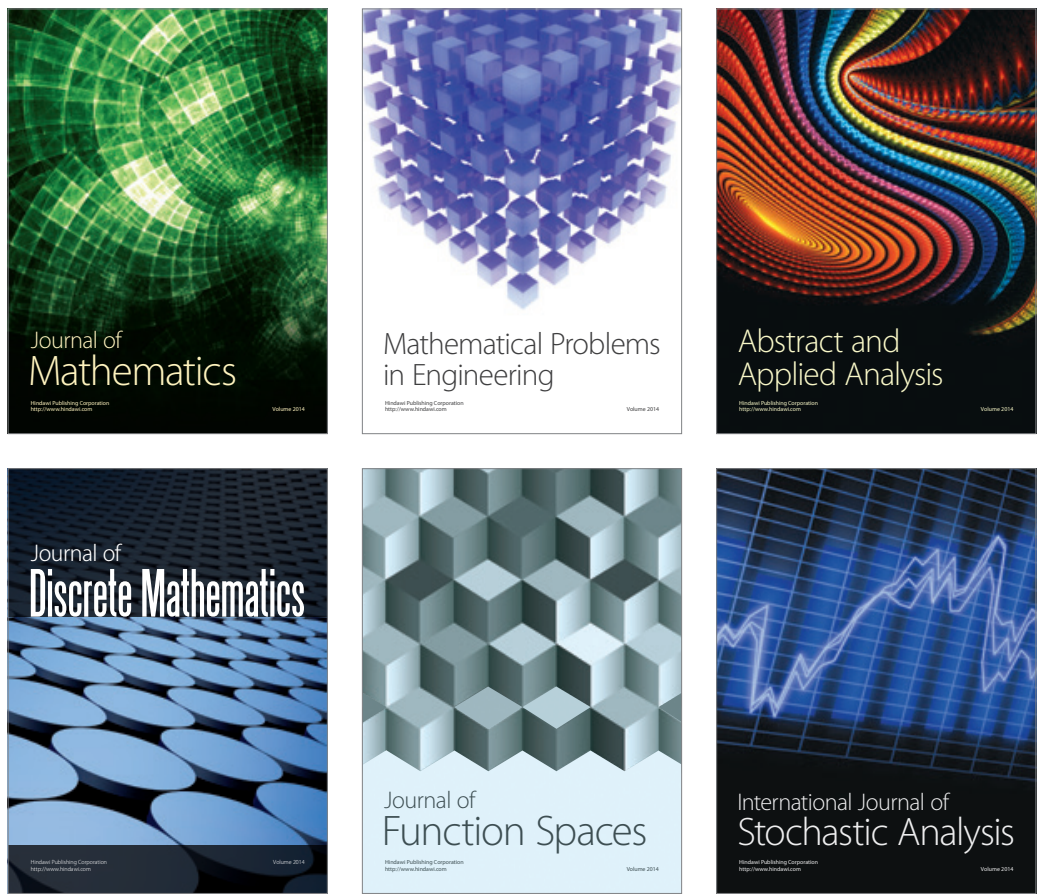

Journal of

Function Spaces

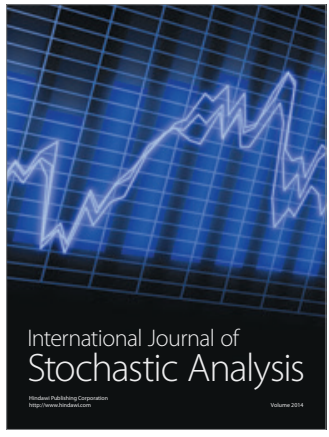

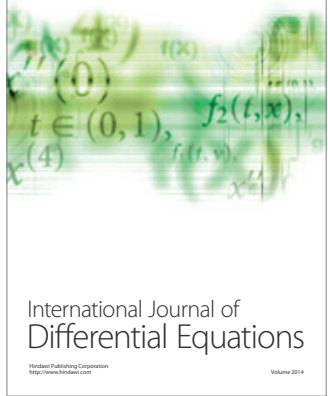
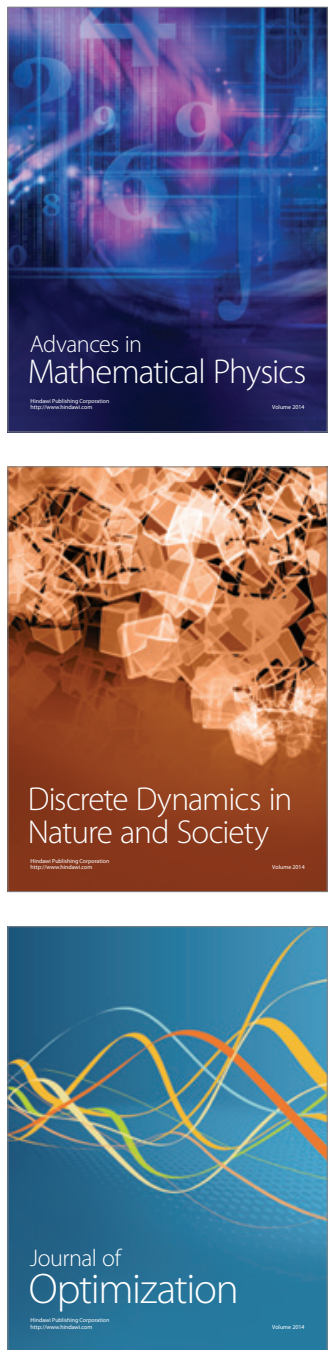